\title{
Digital Learning Ecosystem by Using Digital Storytelling for Teacher Profession Students
}

\author{
Kritsupath Sarnok, Panita Wannapiroon, and Prachyanun Nilsook
}

\begin{abstract}
This research aims 1) to design a Digital Learning Ecosystem, 2) to study the process of teaching digital storytelling in the digital ecosystem, and 3) to evaluate the appropriateness of digital learning ecosystem for teacher profession students. The target audiences were 12 experts in the field of education, information technology, and education communication to evaluate the developed digital learning ecosystem model. Research instruments included the evaluation model of learning. And data analysis used content analysis and use of statistics, mean and standard deviation. The results show that 1) the ecosystem consists of three main components: (1) Digital Learning Ecosystem, consists of Digital Learning Environment and Digital Storytelling, (2) Digital Storytelling Learning Ecosystem, and (3) Digital Storytelling Learning \& Teaching Community. 2) the process of teaching digital storytelling in the digital learning ecosystem consists of: (1) Teaching is responsible by the teacher, IT support staff, supervisor, teaching practicum advisors/school mentor teachers. (2) Learning involves the teacher profession students who must learn from digital devices and the Internet. (3) Supporting includes friends, parents, and guardian. 3) The results of the evaluation of the digital learning ecosystem in overall were in the highest level. When examined in individual aspect, there were 4 items which results were in highest level i.e. Digital Learning Environment $(\overline{\mathrm{X}}=4.61, \mathrm{SD}=0.44)$, Digital Storytelling $(\overline{\mathrm{X}}=\mathbf{4 . 7 5}$, SD = 0.42), Learning $(\bar{x}=4.83, S D=0.39)$ and Supporting $(\bar{x}=$ 4.61, $\mathrm{SD}=0.02)$. The result of the evaluation of the other items was in high level.
\end{abstract}

Index Terms-Digital learning ecosystem, digital storytelling, teacher profession students.

\section{INTRODUCTION}

All occupations are important to the individual and society. It is difficult to say which profession is less or more important. But when teacher profession is considered carefully, it is seen that the teacher is obliged to social responsibilities and country. If the teacher is doing his duty defectively the impact will fall on the decline of society and the country. Therefore, in order for the teacher profession students to be aware of the importance of the teacher profession as the royal speech of the Crown Prince given at the graduation ceremony of the Teachers College on Wednesday, November 26, 1980, that "... duty of the teachers is an important one. It is cultivation of knowledge and mind of the youth in order to grow up to be a good and effective citizen of the nation in the future. The teacher is important for development of the nation and future of the country ... " [1]. And another part, which is the royal speech of HRH Princess Mahachakri Sirindhorn given at the

Manuscript received June 25, 2018; revised July 31, 2018.

The authors are with the King Mongkut's University of Technology North Bangkok, Thailand (e-mail: kritsupath_Sar@vu.ac.th). graduation ceremony of the Teachers College on Wednesday, May 18,1983 , that $" \ldots$ the teacher profession is very important. Because teachers play a key role in developing the country. And before the development of the country, people must be developed which priority is the youth for them to grow up to be completely mature. So they can help to create prosperity to the nation ... " [2]. From the both royal speech, it can be conclude that the teacher is very important. Because teachers are cultivators of feelings, thoughts and minds and are developer of the youth so that they can be important part in the development of the country. Because in order to secure the nation the people in the country must have been developed properly. The development of people will be carried out correctly because the country has a good education system and a good education system to operate effectively because of the good quality teachers.

At present, technological advances and transformations of knowledge on the digital world are endless. Schools and institutions, as well as teachers, need to develop themselves to take themselves into a new world of learning. Adjusting teaching process, technique and teaching media as well as the attitudes, knowledge and understanding of the changing behavior of the learners have resulted in the teacher adjusting and thinking about new teaching methods. Apply modern technology as a medium or tool to create and stimulate learning for new generation of learners [3]. Learning in the new century is a very challenging one for teachers and educational institutions. Therefore, the design of teaching activities and the creation of a new learning society does not focus on educating the learner by the teacher or teacher alone but it is designed to teach and create a learning environment system that focuses on learning and doing activity in anytime through digital technology and tools [4]. From the use of learning and teaching model by digital learning environment, which is the principle of the Digital Ecosystem or the digital learning system. There are a variety of elements in the concept of information and communication technology (ICT) as well as the e-learning system in the field of Information Technology (IT), which include Internet infrastructure [5].

The teaching and learning of digital ecosystems (DTLE) is the creation of relationships in the ecosystem. These include the biotic and the abiotic as well as all physical elements such as equipment, or hardware, operating systems and applications or software, as well as networking technologies. These can all be used with group of learners, instructors, or groups of content creators. All living things are linked together as a learning community within the digital ecosystem [5], [6]. There are different contents within the digital ecosystem itself. It is in the form of a variety of media that are used to search for learning by both instructors and learners 
within the digital ecosystem. Because a part of our life lives in the digital world. The interest and the need to use the technology at all times. For example, in the field of education, such as when the learner is assigned the task, with the skills and abilities of the new learner. Students will be able to analyse and search for information in digital ecosystem. Then present the task in the form of Digital Storytelling which is one of the activities that modern day learners have done so far in the Social Media. The meaning of the media used in digital storytelling is to use digital media and technology to convey the story and emotions of the teller. This digital storytelling is a medium that covers a variety of media such as still image, movies, animations, sounds, video games, content designed for websites, and mobile applications. [7]. All these contents when applied in storytelling by digital technology to gather the media. The story will be suitable for teacher profession students who need to learn to create and access the nature of the teacher. When this method is used, it is considered to be a good way. Because digital storytelling learning focuses on creating media that inspires learners.

Inconclusion, It can be seen that from now on digital media is part of the everyday life of a new generation or group of people called digital natives, as well as everyone who uses it and is part of a digital ecosystem where everything can be used in the learning activities in both formal and informal situations to encourage learners to participate in their own learning process without being confined to the classroom or educational institution With the development of the Digital Learning Ecosystem, teachers, learners, educational institution, and stakeholders can use new learning tools and materials available to offer and share together to make it worthwhile. It is also eco-friendly (Ecology). It also promotes sustainable learning for each student. It is a collaborative learning style in a digital environment that creates media and delivers experiences through digital storytelling that creates a learning experience that uses learning devices with digital and Internet network to facilitate the learning. Learners can control the time, place and direction of learning by themself [8]. The learners have the opportunity to participate in the study, presenting their work which make the learners see their potential, the skills to find information, storytelling, data analysis and synthesis, communicate, presenting, organizing ideas. Questioning, teamwork and lifelong learning awareness. These make changes to the learners abilities and experience using various technologies lead to combination of skills, knowledge, and understanding for teacher profession students in the world of digital learning.

\section{RESEARCH OBJECTIVE}

1) To design a digital learning ecosystem by using digital storytelling learning process for teacher profession students.

2) To study the process of teaching and learning by digital storytelling in the digital learning ecosystem for teacher profession students.

3) To evaluate the appropriateness of digital learning ecosystem and digital storytelling learning process for teacher profession students

\section{SCOPE OF RESEARCH}

1) The population were educational experts with specializations on instructional design and ICT for education.

2) The samples were 6 instructional design experts and 6 ICT for education experts with at least 5-year experience in the fields. They were selected using purposive sampling techniques.

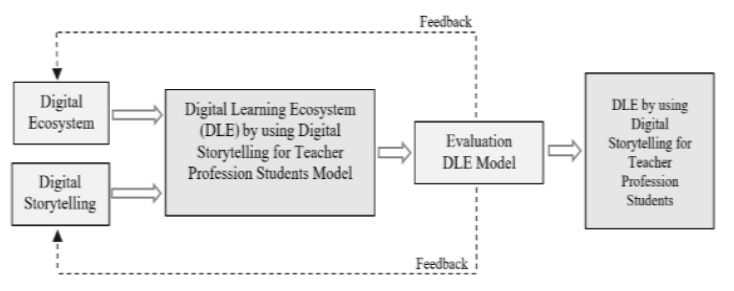

Fig. 1. Conceptual framework.

From Fig. 1 Digital Learning Ecosystem (DLE) consists of two input components i.e. development of a appropriate digital ecosystem to use in facilitating learners and instructor's learning management, encouraging students to realize lifelong learning by giving more freedom to the learners in terms of time control, location and self-learning. In this way, students will have opportunity to participate in the study, presenting idea through digital storytelling to show students potential, information skill, storytelling, data analysis, synthesize, communication skill, presentation skill, organizing ideas, questioning and teamwork. Once the digital learning ecosystem has been developed, in the next step, the system will be evaluated by experts and revise to gain the most appropriate model to develop Digital Learning Ecosystem by Using Digital Storytelling for Teacher Profession Students.

\section{RESEARCH METHODS}

The researcher reviewed previous studies in the field and developed the Digital Learning Ecosystem by using Digital Storytelling for teacher profession students. This covered 9 steps as follows:

1) Reviewed of literature and previous studies regarding Digital Ecosystem, Digital Storytelling and teacher profession students to study the model, characteristics, and previous research.

2) Studied relevant studies of Digital learning Ecosystem design by using Digital Storytelling.

3) Conducted front-end analysis in three parts: 1) Context analysis including needs analysis, curriculum analysis and module analysis, 2) Learner analysis including new generations' lifestyle, needs for education, accessibility to content knowledge and the critical thinking and 3) Learning task analysis.

4) Designed Digital Learning Ecosystem by using Digital Storytelling for teacher profession students follows the design steps of AAA Model [9] as follows: Part 1) Analysis or three parts analysis which include Instructor, Learner \& Digital Learning Environment. Part 2) Activity or Digital Storytelling activity. Part 3) Authentic 
Assessment Learning in Digital Learning Ecosystem to apply the information obtained to improve the Digital Learning Ecosystem by Digital Storytelling for teacher profession students.

5) Developed Digital Learning Ecosystem which can be divided into 3 parts as follow: Part 1) Instructor, Part 2) Learner \& Part 3) the learning environment using digital storytelling process.

6) Had the developed learning activity model checked and revised by the research advisor.

7) Creating evaluation tools to evaluate the validity of digital learning ecosystem by digital storytelling which consists of with 3 main components: 1) Digital Learning Ecosystem consists of 2 sub-sections include 9 assessment items. 2) Digital Storytelling Learning Ecosystem consists of 2 sub-section, 11 assessment items, 3) Digital Storytelling Learning \& Teaching Community consists of 3 sub-sections including 7 assessment items.

8) Had the instrument checked for content validity through the Index of Item Objective Congruence (IOC) by 5 experts. The selected questionnaire ranged between $0.50-1.00$. It was found that the suitability of questionnaire from the IOC was at 0.85 .

9) Had the Digital Learning Ecosystem by using Digital Storytelling for teacher profession students model checked for the suitability by 12 experts and made a conclusion.

\section{RESUlTS}

The results of the developed Digital Learning Ecosystem by using Digital Storytelling for teacher profession students are as follows:

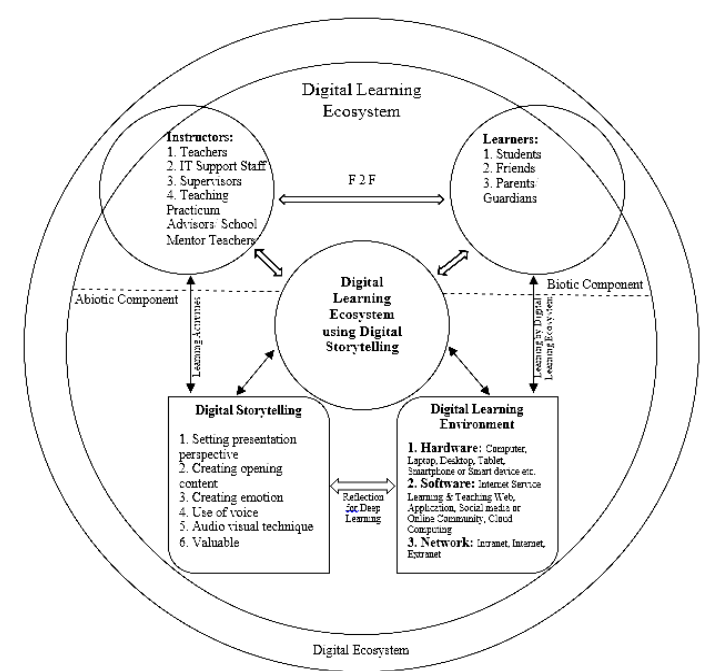

Fig. 2. Digital learning ecosystem by using digital storytelling for teacher profession students.

1) Biotic component consists of two groups:

- Groups of instructors including instructors, IT support staff, supervisors, teaching practicum advisors/ school mentor teachers.

- Group of students including students, friends and parents, guardians

2) Abiotic component consists of two parts:

- Digital Storytelling $\checkmark$ Setting presentation perspective

$\checkmark$ Creating opening content

$\checkmark$ Creating emotion

$\checkmark$ Use of voice

$\checkmark$ Audio visual technique

$\checkmark$ Valuable

- Digital Learning Environment

$\checkmark$ Hardware: Computer, Laptop, Desktop, Tablet, Smartphone or Smart device etc.

$\checkmark$ Software: Internet Service Learning \& Teaching Web, Application, Social media or Online Community, Cloud Computing

$\checkmark$ Network: Intranet, Internet, Extranet.

From the model of Digital Learning Ecosystems by using digital storytelling for teacher profession students. When the components are separated, the components are as shown in Fig. 3.

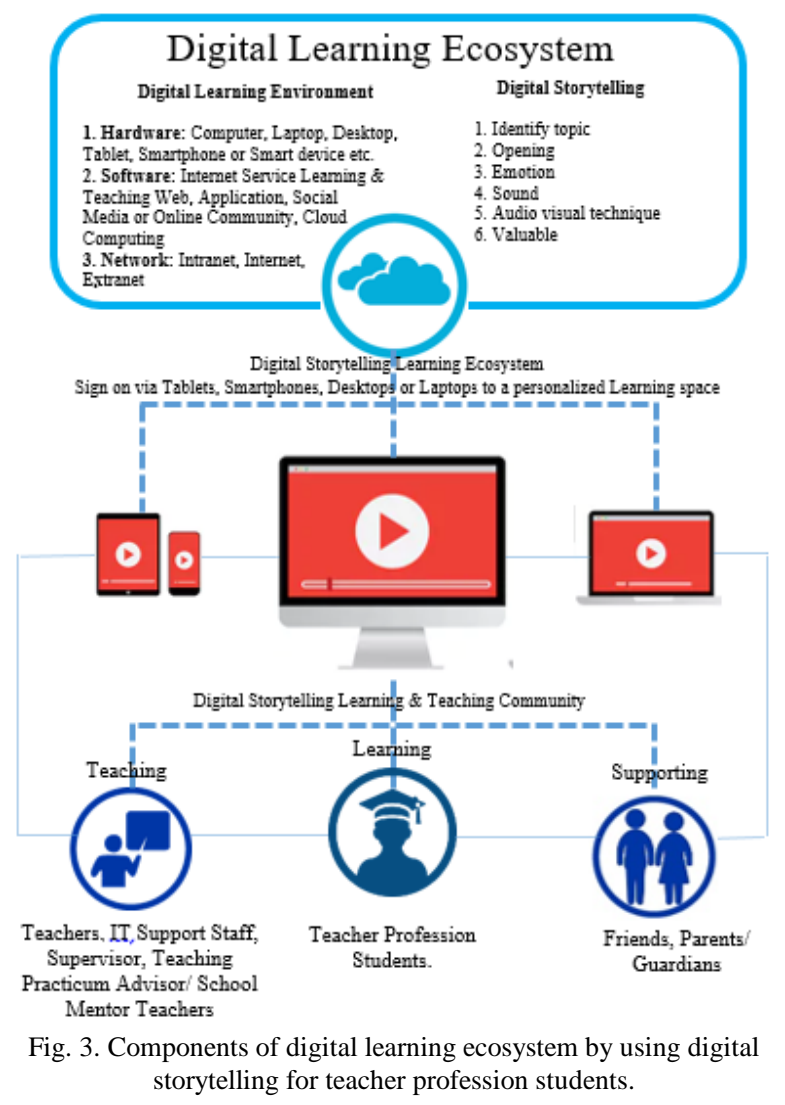

Fig. 3 shows components of Digital Learning Ecosystem by using Digital Storytelling for teacher profession students as follow:

1) Digital Learning Ecosystem consists of two components:

- Digital Learning Environment setting consists of different learning tools such as 1) Hardware i.e. Computer, Laptop, Desktop, Tablet, Smartphone or Smart device etc. 2) Software i.e. Internet Service Learning \& Teaching Web, Application, Social media or Online Community, Cloud Computing 3) Network i.e. Intranet, Internet, Extranet.

- Digital Storytelling consists of six factors that affect the effectiveness of digital learning medias

$\checkmark$ Setting presentation perspective. There are 3 types of presentations: Present the story needs to communicate through own perspective, story from direct experiences. 
The second is to present the story through other person perspective which is a like observing the events. And the last one is presenting in the perspective of the third person, who is not directly involved in the event but knows the events well and able to access and convey all the ideas of the characters.

$\checkmark$ Creating opening content means to make the story interesting by opening the question from the beginning to make people who are watching or listening want to know and want to keep observing to find the answer to that question.

$\checkmark$ Creating emotions means to create atmosphere of shared emotions between contents and the audiences to share feeling with the contents such as laugh, cry, excited, etc.

$\checkmark$ The use of voice means to create or choose the right voice, tone, the mood of the story from the voice such as to build or encourage the audiences to follow the content, do not bore or use to make things more interesting.

$\checkmark$ Audio visual technique means analytical thinking, planning for proper use of audio visual media. It can communicate clearly to the emotions of the audience, attract attention of the audience to concentrate until the end.

$\checkmark$ Valuable means after observing the contents the audiences gain knowledge and sense of the importance of the media. The media may not need to use a lot of budgeting tools or techniques.

2) Digital Storytelling Learning Ecosystem

Digital Storytelling Learning Ecosystem is the learning of learners using electronic devices such as tablets, smartphones, desktops or laptops. In learning, learners can learn anywhere and at any time from digital media and technology that stories and emotions of narrators are conveyed through digital storytelling from a variety of media including still images, short film, animation, audio, video game, applications or content on the sites designed on Cloud.

3) Digital Storytelling Learning \& Teaching Community consists of 3 components as detail as follow:

- Teaching is an important part because it is the part that educates and assists in learning through the content of digital storytelling in ecosystem. This includes teachers, IT support staff, supervisors, teaching practicum advisors/school mentor teachers. All related parties must be trained to provide teacher profession students with professional knowledge, skills and experience in accordance with the professional standards of the Council of Teachers and due to duties as follow:

$\checkmark$ Teachers are responsible in teaching the courses in the curriculum covering profession course, majors and electives courses.

$\checkmark$ IT Support Staff are responsible for training and support of equipment, materials and technologies used for the learning of teacher profession students.

$\checkmark$ Supervisors are responsible for supporting, counseling and help in studying and living including training to be a good teacher in the future.

$\checkmark$ Teaching Practicum Advisors/ School Mentor Teachers are responsible for providing counseling and supports the teaching experience in schools.

- Learning means the teacher profession students who must learn from digital devices and the Internet. The learners can control their own time, place and learning direction. In learning, students will have the opportunity to participate in the study, present their work through digital storytelling which make the students see their potential, improve the skills to find information, storytelling, data analysis, data synthesize, communicate, presentation, organize ideas, questioning, and teamwork and lifelong learning awareness.

- Supporting is the backstop that support, give advice, and encourage the learners in real-life learning and digital ecosystem learning. This group includes friends, parents and guardian.

\section{RESUlTS OF EVALUATION}

Criteria for determining mean were as follows:

Mean 4.51-5.00 Curriculum appropriateness at highest level

Mean 3.51-4.50 Curriculum appropriateness at high level

Mean 2.51-3.50 Curriculum appropriateness at medium level

Mean 1.51-2.50 Curriculum appropriateness at low level

Mean 1.00-1.50 Curriculum appropriateness at lowest level Results of Evaluation of Digital Learning Ecosystem

Table I. The evaluation of the appropriateness of the digital learning of the ecosystem based on digital learning Ecosystem by using Digital Storytelling for teacher profession student. The overall results of the study were highest level ( $\overline{\mathrm{X}}=4.54, \mathrm{SD}=0.21)$ When examined in individual aspect, there were 4 aspect which result were highest level e.g. Digital Learning Environment $(\overline{\mathrm{x}}=4.61, \mathrm{SD}$ $=0.44)$, Digital Storytelling $(\overline{\mathrm{X}}=4.75, \mathrm{SD}=0.42)$, Learning $(\overline{\mathrm{X}}=4.83, \mathrm{SD}=0.39)$, and supporting $(\overline{\mathrm{X}}=4.61, \mathrm{SD}=0.02)$. The other results were in high level. The details are as follows.

TABLE I: OVERALl EVALUATION RESUlT OF DIGITAL LEARNING ECOSYSTEM

\begin{tabular}{|c|c|c|c|}
\hline \multirow[t]{2}{*}{ Issues } & \multicolumn{3}{|c|}{ Level of appropriateness } \\
\hline & $\bar{x}$ & S.D. & Description \\
\hline \multicolumn{4}{|l|}{ 1. Digital Learning Ecosystem } \\
\hline 1.1 Digital Learning Environment & 4.61 & 0.44 & Highest \\
\hline 1.2 Digital Storytelling & 4.75 & 0.42 & Highest \\
\hline \multicolumn{4}{|l|}{ 2. Digital Storytelling Learning } \\
\hline \multicolumn{4}{|l|}{ Ecosystem } \\
\hline 2.1 Learning Equipment & 4.10 & 0.09 & High \\
\hline 2.2 Digital Storytelling Learning & 4.45 & 0.54 & High \\
\hline \multicolumn{4}{|l|}{ 3. Digital Storytelling Learning } \\
\hline \multicolumn{4}{|l|}{ \& Teaching Community } \\
\hline 3.1 Teaching & 4.46 & 0.10 & High \\
\hline 3.2 Learning & 4.83 & 0.39 & Highest \\
\hline \multirow[t]{2}{*}{ 3.3 Supporting } & 4.61 & 0.02 & Highest \\
\hline & 4.54 & 0.21 & Highest \\
\hline
\end{tabular}

From Table I It can be split in detail of the evaluation result in individual aspect as in Table II.

From Table II. When examined in individual aspect, it appears that there were 19 items the evaluation results received the highest level. The remaining 8 items received high level. When examined the results, the highest score was 
the teachers aspect $(\overline{\mathrm{X}}=4.92, \mathrm{SD}=0.29)$. The Digital Storytelling Learning \& Teaching Community and the value proposition of digital storytelling media $(\overline{\mathrm{X}}=4.92, \mathrm{SD}=0.29)$. In addition, the lowest scores were the Desktops $(\overline{\mathrm{X}}=3.50$, $\mathrm{SD}=0.52)$ and digital storytelling media in website model $(\overline{\mathrm{X}}=3.92, \mathrm{SD}=0.79)$

TABLE II: INDIVIDUAL ASPECT EVALUATION RESULT OF DIGITAL LEARNING ECOSYSTEM

\begin{tabular}{|c|c|c|c|}
\hline \multirow[t]{2}{*}{ Issues } & \multicolumn{3}{|c|}{ Level of appropriateness } \\
\hline & $\bar{x}$ & S.D. & Description \\
\hline \multicolumn{4}{|l|}{ 1. Digital Learning Ecosystem } \\
\hline 1.1 Digital Learning & 4.61 & 0.44 & Highest \\
\hline Environment & 4.67 & 0.44 & Highest \\
\hline 1.1.1 Hardware & 4.42 & 0.49 & High \\
\hline 1.1.2 Software & 4.75 & 0.38 & Highest \\
\hline 1.1.3 Network & 4.75 & 0.42 & Highest \\
\hline \multicolumn{4}{|l|}{ 1.2 Digital Storytelling } \\
\hline 1.2.1 Setting presentation & 4.75 & 0.45 & Highest \\
\hline perspective & 4.67 & 0.49 & Highest \\
\hline 1.2.2 Creating opening & 4.83 & 0.39 & Highest \\
\hline content & 4.50 & 0.52 & Highest \\
\hline 1.2.3 Creating emotion & 4.83 & 0.39 & Highest \\
\hline 1.2.4 Use of voice & 4.92 & 0.29 & Highest \\
\hline \multicolumn{4}{|l|}{ 1.2.5 Audio visual technique } \\
\hline \multicolumn{4}{|l|}{ 1.2.6 Valuable } \\
\hline \multicolumn{4}{|l|}{ 2. Digital Storytelling Learning } \\
\hline \multicolumn{4}{|l|}{ Ecosystem } \\
\hline 2.1 Learning Equipment & 4.10 & 0.09 & High \\
\hline 2.1.1 Tablets & 4.00 & 0.60 & High \\
\hline 2.1.2 Smartphones & 4.75 & 0.45 & Highest \\
\hline 2.1.3 Desktops & 3.50 & 0.52 & Highest \\
\hline 2.1.4 Laptops & 4.17 & 0.39 & Highest \\
\hline 2.2 Digital Storytelling & 4.45 & 0.54 & High \\
\hline Learning & 4.00 & 0.74 & High \\
\hline 2.2.1 Still image & 4.75 & 0.45 & Highest \\
\hline 2.2.2 Short film & 4.75 & 0.45 & Highest \\
\hline 2.2.3 Animation & 4.25 & 0.45 & High \\
\hline 2.2.4 Audio & 4.67 & 0.49 & Highest \\
\hline 2.2.5 Game & 4.83 & 0.39 & Highest \\
\hline 2.2.6 Application & 3.92 & 0.79 & High \\
\hline \multicolumn{4}{|l|}{ 2.2.7 Website } \\
\hline \multicolumn{4}{|l|}{ 3. Digital Storytelling Learning } \\
\hline \& Teaching Community & 4.46 & 0.10 & High \\
\hline 3.1 Teaching & 4.92 & 0.29 & High \\
\hline 3.1.1 Teacher & 4.33 & 0.49 & Highest \\
\hline 3.1.2 IT support staff & 4.42 & 0.51 & Highest \\
\hline \multicolumn{4}{|l|}{ 3.1.3 Supervisor } \\
\hline \multicolumn{4}{|l|}{ 3.1.4 Teaching practicum } \\
\hline advisor/School mentor & 4.17 & 0.39 & Highest \\
\hline teacher & 4.83 & 0.39 & Highest \\
\hline 3.2 Learning & 4.61 & 0.02 & Highest \\
\hline 3.3 Supporting & 4.67 & 0.49 & Highest \\
\hline 3.3.1 Friends & 4.67 & 0.49 & Highest \\
\hline 3.3.2 Parents & 4.50 & 0.52 & Highest \\
\hline 3.3.3 Guardians & & & \\
\hline
\end{tabular}

\section{DISCUSSION THE RESULTS}

The model of Digital Ecosystem Learning by Digital Storytelling for teacher profession students consists of 3 main components:

1) The Digital Learning Ecosystem, which consists of 2 parts e.g. Digital Learning Environment that incorporates Hardware, Software and Network, in accordance with Mart Laanpere, Kai Pata. , Peeter Normak, and Hans Põldoja, who said that digital ecosystems should be designed with the environment, tools and equipment that support the teaching of the teachers to support teachers in online learning. [10] The second part is Digital Storytelling composed of six factors that affect the efficiency of digital storytelling: creating a presentation perspective, creating opening content, emotion, use of voice, use audio visual techniques, and valuable in accordance with Joe Lambert and Kimmo Vänni discuss the 7 Step Digital Storytelling process: Step 1: Owning Your Insights, 2: Owning Your Emotions, 3: Finding the Moment, 4: Seeing Your Story, 5: Hearing Your Story, 6: Assembling Your Story and 7: Sharing Your Story [11], [12].

2) Digital Storytelling Learning Ecosystem is Learning from content that is in the form of digital storytelling. In learning, learners will use electronic media to learn a variety of media, including still images, short films, animations, audio, video games, applications, or content designed on a cloud-based website. Which in accordance with Halah Ahmed Alismail discusses the integration of digital storytelling in $21^{\text {st }}$ century education; technology is a key in education for new generation. Teachers should use the learning management to make a positive impact on students' learning by integrate digital storytelling in digital multimedia. Use of teaching tools including synthesizing, analyzing, evaluating, presenting, and interacting with technology [13]. Bernard R. Robin mentioned the use of digital storytelling in teaching, he mentioned that over the past 20 years, many educators, students and others around the world have created short films in the form of multimedia and video clips as well as music to present content to support teaching activities [14].

3) The Digital Storytelling Learning \& Teaching Community consists of 3 components: 1) Teaching consists of teachers, IT support staff, supervisor, teaching practicum advisors/school mentor teachers. 2) learning, and 3) supporting consists of friends, parents, and guardian. [15] - [16] The application of the digital learning environment, Hayeewangah, N., Wannapiroon, P., \& Jeerungsuwan, N., mentioned the dimensions that need to be addressed including student dimensions. The learner must control his/ her learning style. There are a variety of learning methods that lead to lifelong learning. And the second dimension is dimension of the environment should be promoted and supported from the situation, work experience, life experience, personal, family, community, society [17].

\section{SUGGESTIONS}

To provide a Digital Learning Ecosystem with digital storytelling for teacher profession students, consideration should be given to the educational component and the availability of technology and should consider the majors of the teacher profession student. Content used to teach and support for internal technology, both in faculty and university's policies. Phumeechanya, N., Wannapiroon, P., \& Nilsook, $\mathrm{P}$, mentioned that teaching must be aware of the learner context. The U-Learning environment known as the Ubiquitous Learning Environment (ULE) is a learning 
environment that brings learning anywhere and learning can happen at any time through portable computers to access to learning resources. The ULE environment consists of: 1) mobile device 2) wireless communication 3) Ubiquitous learning management system and 4) learning context detection [18]. In addition to the above, the consideration for the Digital Learning Ecosystem, the subject of teaching or learning management is considered very important. Digital Storytelling teaching techniques used for teaching the teacher profession students in Digital Ecosystems will be useful for many purposes, such as creating skills for addressing issues of the subject, presentation skills, communication skills which are essential for future teachers. In accordance with Bernard R. Robin, Digital Storytelling is a powerful learning tool for both learners and those in the educational field. It can be used to support teaching and is a way for learners to learn from their digital creations [19]. But in the digital production process as a content for learning in digital ecosystems, it should have analytical methods, stages of development, scripts, pararell with researching [20]. This is to create quality digital storytelling content in digital ecosystems, can be used in both formal and informal education.

\section{ACKNOWLEDGMENT}

The researcher would like to thank Vongchavalitkul University and King Mongkut's University of technology North Bangkok for their full support and promotion of this research.

\section{REFERENCES}

[1] Bangkok Today News. (2017). "King Rama X" with Education \& Royal Guidance. [Online]. Available: http://bangkok-today.com/web/qi7pt

[2] Office of the Education Council. (2018). Teacher Guide: Royal Guidance Her Royal Highness Princess Maha Chakri Sirindhorn Congratulate to Graduate School Teachers Nationwide 1983. [Online]. Available: http://www.onec.go.th/index.php/book/BookView/610

[3] K. Sarnok, "IoE links everything to smart classroom 4.0," presented at the National Academic Conference on Education 3th "NACE 2017 Innovation of learning" Meeting, Lampang, Thailand, July 29, 2017.

[4] K. Sarnok, and P. Wannapiroon, "Connectivism learning activity in ubiquitous learning environment by using IoE for digital native," Veridian E-Journal International (Humanities, Social Sciences and Arts), vol. 11, no. 4, pp. 405-418, January-June 2018.

[5] J. Reyna, "Digital teaching and learning ecosystem (DTLE): A theoretical approach for online learning environments," in Proc. Ascilite 2011 Hobart: Concise Paper, pp. 1080-1088, 2011.

[6] I. K. Ficheman and R. D. Lopes, "Digital learning ecosystem: Authoring, collaboration, immersion and mobility," presented at Eighth IEEE International Conference on Advanced Learning Technologies, 2018.

[7] P. Wannapiroon, "Information technology and educational innovation," Faculty of Industrial Education, King Mongkut's University of Technology North Bangkok, 2016, pp. 159-161.

[8] Michael Carrier \& Highdale Learning, "Digital learning trends 2017-2020," QLS 2017, Thessalonica, pp. 1-61, 2017.

[9] N. Jeerungsuwan. "Instructional design and assessment," Faculty of Industrial Education, King Mongkut's University of Technology North Bangkok, 2016, pp. 1-278.

[10] M. Laanpere et al., "Pedagogy-daiven design of digital learning ecosystems," Computer Science and Information Systems, vol. 11, no. 1, pp. 419-442.

[11] J. Lambert, "Digital storytelling COOKBOOK," Center for Digital Storytelling, January, 2010. pp. 1-40.
[12] K. Vänni. (October, 25, 2017). Storytelling seven steps. TAMK/Paja [Online]. Available: https://research.uta.fi/innovaatiokausi/wpcontent/uploads/sites/28/20 17/08/Digital-Story-Telling.pdf

[13] H. A. Alismail, "Integrate digital storytelling in education," Journal of Education and Practice, vol. 6, no. 9, 2015, pp. 126-130.

[14] B. R. Robin, "The power of digital storytelling to support teaching and learning," Digital Education Review - Number 30, December 2016. pp. 17-29.

[15] I. F. Silveira et al., "A digital ecosystem for the collaborative production of open textbooks: The LATIn methodology," Journal of Information Technology Education: Research, vol. 12, 2013, pp. 225-249.

[16] M. Marcuss, "Digital storytelling as a community development strategy," Federal Reserve Bank of Boston, pp. 9-13.

[17] N. Hayeewangah, P. Wannapiroon, and N. Jeerungsuwan, "Information technology and communication to enhance non-formal educational society," Journal of Education Prince of Songkla University, Pattani Campus, vol. 23, no. 3, Sep-Dec 2012, p. 28.

[18] N. Phumeechanya, P. Wannapiroon, and P. Nilsook, "Ubiquitous scaffolding learning management system," in Proc. National Conference on Educational Technology 2015: NCET 2015, Jan 2015, pp. 22-33.

[19] B. R. Robin, "The educational uses of digital storytelling," University of Houston, pp. 1-8.

[20] A. Gubrium and K. C. N. Turner, "Digital storytelling as an emergent method for social research and practice," Aline Gubrium, June 2014, pp. 469-491.

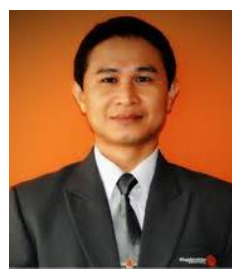

Kritsupath Sarnok is a Ph.D. candidate, Division of Information and Communication Technology for Education, Faculty of Technical Education, King Mongkut's University of Technology North Bangkok (KMUTNB) and He is lecturer at the Department of Technology and Computer, Faculty of Education, Vongchavalitkul University, Thailand.

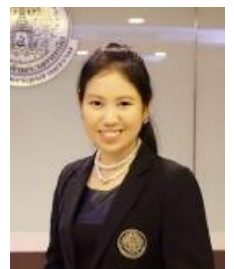

Panita Wannapiroon is an associate professor in the Division of Information and Communication Technology for Education, the Faculty of Technical Education at King Mongkut's University of Technology North Bangkok (KMUTNB), Bangkok, Thailand. She has experience in many positions such as the director at Innovation and Technology Management Research Center, assistant director of Online Learning Research Center, assistant director of Vocational Education Technology Research Center, and assistant director of Information and Communication Technology in Education Research Center. She also received the Burapha University Thesis Award 2002. And she is a membership of professional societies in Association for Educational Technology of Thailand (AETT).

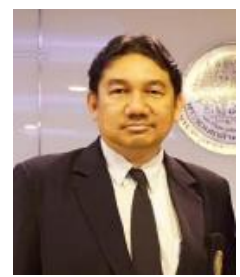

Prachyanun Nilsook is an associate professor at Division of Information and Communication Technology for Education, Faculty of Technical Education, King Mongkut's University of Technology North Bangkok (KMUTNB), Thailand. He received the B.Ed. in audio-visual education, from Faculty of Education, Ramkhamhang University, He obtained his M.Ed. in educational technology from, Srinakarinwirot University, and received the Ph.D. in educational communications and technology from Chulalongkorn University. From 2001 to present, he works in the field of information and communication technology in education. He has experience in many positions such as the dean, the faculty of technical education, Samutsongkhram Technical Collage and the Head of Vocational Education Technology Research Center. He received National Teachers Award of the Year in Higher Education 2004 from National Teacher Council, Ministry of Education, and Thailand. He is a membership of Professional Societies in Association for Educational Communication and Technology of Thailand (AECTT). 